\title{
Genetic structure of root distribution in genotype crosses of Mesoamerican common bean
}

\author{
R.C. de Melo ${ }^{1}$, P.H. Cerutti ${ }^{1}$, F.A.C. Nardello ${ }^{1}$, A.F. Guidolin ${ }^{1}$, \\ J.G.C. da Silva ${ }^{2}$ and J.L.M. Coimbra ${ }^{1}$ \\ ${ }^{1}$ Universidade do Estado de Santa Catarina, Departamento de Agronomia, \\ Instituto de Melhoramento e Genética Molecular, Lages, SC, Brasil \\ ${ }^{2}$ Universidade Federal de Pelotas, Faculdade de Agronomia Eliseu Maciel, \\ Departamento de Fitotecnia, Capão do Leão, RS, Brasil
}

Corresponding author: R.C. de Melo

E-mail: rita_carol_mel@hotmail.com

Genet. Mol. Res. 21 (1): gmr18986

Received October 19, 2021

Accepted December 22, 2021

Published January 31, 2022

DOI http://dx.doi.org/10.4238/gmr18986

\begin{abstract}
Knowledge of the genetic structure of a trait shapes the entire strategy of a breeding program. In this study, the purpose was to determine the additive and non-additive effects that affect the genetic control of common bean roots. A field experiment, with 75 treatments in a partially balanced incomplete block design, was carried out in the 2018/19 growing season. The treatments consisted of backcross progenies $\left(\mathrm{L}_{1}-\mathrm{P}_{1} \times \mathrm{F}_{2}, \mathrm{~L}_{2}-\mathrm{P}_{2} \times \mathrm{F}_{2}\right.$ and $\left.\mathrm{L}_{3}-\mathrm{F}_{1} \times \mathrm{F}_{2}\right)$ resulting from a Triple Test Cross mating design, with the Mesoamerican parents $\mathrm{P}_{1}$-BAF50 (accession of the active germplasm bank) and $\mathrm{P}_{2}$-IPR Uirapuru (commercial cultivar). The trait root distribution was assessed based on the soil excavation method, in situ. To this end, trenches were opened under each plant (two plants per replication, in each treatment) and a grid was inserted in the open profile. Pictures were taken of the grid in the trench, based on which the root distribution (percentage) could be quantitatively assessed. To compare root and shoot biomass, the numbers of pods and grains were counted at harvest. The treatment factor was partitioned into genetic effects (additive, dominant and epistatic) by the establishment of predictive functions. The additive genetic effect was the most
\end{abstract}


influential in the genetic trait control. On the other hand, additive $\times$ additive epistasis caused no significant deviation from the genotypic value of plants, neither for roots $(\mathrm{P}=0.7941)$ nor grain yield components. Among the evaluated progenies, effects of dominance deviation and additive $\mathrm{x}$ dominant and dominant $\mathrm{x}$ dominant epistasis were observed least often, and the expression in the trait root distribution had opposite directions (positive and negative deviations), whereas for the yield components, the nonadditive gene effects had one and the same pattern. In crosses between Mesoamerican genotypes, the genetic value of roots is based on the average genetic effects alone, while the genetic interactions are negligible.

Key words: Phaseolus vulgaris; Quantitative genetics; Dominance deviations; Epistasis; Generalized linear mixed model

\section{INTRODUCTION}

The number of studies related to the root system of agricultural crops has increased greatly in the last decade (Burridge et al., 2016, 2019; Muller et al., 2019; Bárzana and Carvajal, 2020). Climatic adversities and the need for high quantity and quality food, even under limiting cultivation conditions, kindled the interest to study traits "hidden" in the soil (Bishopp and Lynch, 2015). Plant roots play an important role in nutrient and water uptake and are consequently related to photosynthesis and directly to agricultural crop productivity (Tracy et al., 2020). Common bean is the main legume used for direct consumption by humans. However, the crop is highly sensitive to the major abiotic stresses, e.g., aluminum toxicity (Ambachew and Blair, 2021) and water deficit (Heinemann et al., 2017). In this sense, advancing knowledge about roots could be useful to develop genotypes with greater plasticity in these scenarios.

With a view to overcoming these limitations, common bean breeding programs have advanced the genetic characterization of roots (Polanía et al., 2012), the understanding of root distribution and how this trait is related with drought adaptation (Rosales et al., 2012; Lanna et al., 2016; Polanía et al., 2017), as well as the development of phenotyping methods (Burridge et al., 2016) and molecular approaches, e.g., QTL mapping (Teran et al., 2019). However, the inclusion of trait root distribution and the generation of superior genetic constitutions in a breeding program are only possible if the genetic structure of the populations is thoroughly understood. Based on the comprehension of how segregating populations behave across generations of selfing, the breeder can define the breeding strategies, crosses, methods, and selection pressure to be used (Bos and Caligari, 1995).

The genetic control of a polygenic trait such as roots is mediated by the relationship between related plants, derived from a specific mating design (Nduwumuremyi et al., 2013). Once the segregating populations are established, the following values can be defined: i) genetic value of plants, which is the sum of the average genetic effects, ii) deviations due to dominance, i.e., interactions between alleles within a locus, and iii) deviations due to epistasis, i.e., additional deviations caused by non-additive combinations (Falconer, 1987). The latter component of genotypic value has rarely been studied in genetic inheritance models. The importance of epistasis for the inheritance of quantitative traits is still not fully clarified, which is why most models ignore this genetic effect (Kearsey and Jinks, 1968). 
Epistasis is a key element in quantitative genetic models for the prediction of similarities among relatives (Hansen, 2013) and is taken into consideration when phenomena such as heterosis and inbreeding are involved (Kusterer et al., 2007; Melchinger et al., 2007; Shen et al., 2014; Shang et al., 2016). In other words, this genetic effect can be exploited in allogamous as well as autogamous crops. Maize breeding programs targeting crosses, for example, are extremely effective in selecting favorable epistatic combinations, since the inbreeding generations are cultivated alongside the hybrids under evaluation, and favorable combinations can be fixed in the lines (Lamkey et al., 1995). In autogamous crops such as common bean, only the additive $\mathrm{x}$ additive component is relevant, as these effects can be fixed during the selfing generations.

In view of the above, since knowledge of inheritable variation is essential to correctly define the type of selection of superior genetic material, the objective of this study was to determine the additive and non-additive effects that affect root inheritance of a controlled cross between Mesoamerican common bean genotypes.

\section{MATERIAL AND METHODS}

\section{Experimental and breeding design}

The experiment was carried out in the field in Lages (Santa Catarina state, Brazil) from December 2018 to March 2019 (recommended season for common beans in Lages). The characteristics of the location, soil, and physical/chemical properties, as well as the prevailing meteorological conditions during the experimental period are listed in Figure S1.

The progenies of the trial were planted, arranged in a partially balanced incomplete block design 15 x 5 ( 75 treatments), with two replications. The experimental units consisted of two $1.5-\mathrm{m}$ rows in which three seeds were sown, i.e., a total of six plants per plot. The plant density (spacing of $0.5 \mathrm{~m}$ between plants and rows) allows the maximum root development of a single common bean plant, without physical obstacles. In this way, the treatments can be compared and the genetic components determined.

Based on the principle of using contrasting genotypes to investigate the inheritance of a trait, evaluations in previous years qualified BAF50 (accession of the Active Common Bean Germplasm Bank of the State University of Santa Catarina - UDESC) and IPR Uirapuru (commercial cultivar released by the breeding program of the Agricultural Research Institute of Paraná - IAPAR) as suitable for this study The average root distribution of the parents was $57 \%$ (BAF50) and 35\% (IPR Uirapuru). In addition, BAF50 and IPR Uirapuru were contrasting in the traits growth habit (type III and type II, respectively) and commercial group (carioca and black, respectively).

The hybridization between the genetic constitutions was carried out with the emasculation of the floral bud, in a greenhouse. Two seeds of each parent were sown in 10 pots and thinned to one plant per pot for hybridizations. Fractions of the resulting $F_{1}$ seeds were sown in plant pots to establish $F_{1}$ plants and after selfing, $F_{2}$ seeds. With the above genotypes $\left(\mathrm{P}_{1}, \mathrm{P}_{2}\right.$, $\mathrm{F}_{1}, \mathrm{~F}_{2}$ ) it was possible to apply a half-sib Triple Test Cross (TTC) mating scheme by which each $\mathrm{F}_{2}$ plant is backcrossed with three testers: $\mathrm{P}_{1} \times \mathrm{F}_{2}\left(\mathrm{~L}_{1}\right), \mathrm{P}_{2} \times \mathrm{F}_{2}\left(\mathrm{~L}_{2}\right)$ and $\mathrm{F}_{1} \times \mathrm{F}_{2}\left(\mathrm{~L}_{3}\right)$ (Kearsey and Pooni, 1996).

\section{Response variables}

During the characterization of the genotypes to choose the parents, among all evaluated root-related traits (root dry matter, total length, number of intersections and distribution), the 
trait root distribution was considered the most discriminating according to statistical analyses in previous studies. In addition, this trait is related to all other root parameters. Root distribution is related to the extent to which a genotype can take exploit the soil resources (water and nutrients). The better the roots are distributed in the evaluated plane (horizontal and depth), the greater the plant capacity to acquire resources from the soil.

Root distribution was evaluated according to the excavation method, described in the publication "Methods of Studying Root Systems" (Böhm, 1979), with adaptations. In a first step, the method involves the generation of a clear image of the entire natural root system of a single plant. Based on the photograph, visual morphological aspects of the roots can be described. However, for a quantitative evaluation of the trait, two plants per plot (four plants, considering the replications) in stage R6 (flowering) were evaluated, according to the CIAT scale. At this stage, a trench $(0.50 \mathrm{~m}$ long, $0.30 \mathrm{~m}$ deep) was opened in the soil beside each plant, perpendicular to the planting line (cut in the soil), at a standard distance of $0.05 \mathrm{~m}$ from the respective plant. Thereafter, excess soil was removed to expose the roots of the excavated profile. Another modification of the method was the use of a frame divided into $0.05 \mathrm{~m}$ grid squares (same size as the soil profile) near the roots (Figure 1a). A photograph of this template was analyzed for presence or absence of roots, in a binary evaluation ( 1 or 0 , for each grid) (Figure $1 \mathrm{~b})$. In this way, the root percentage of each profile was defined $\left(\left(\sum 1 / 60\right) * 100\right)$.

At harvest maturity (R9), the number of pods per plant and number of grains per plant were determined to compare the root and shoot traits. The traits evaluated with the respective measurement units and distributions are summarized in Table S1.

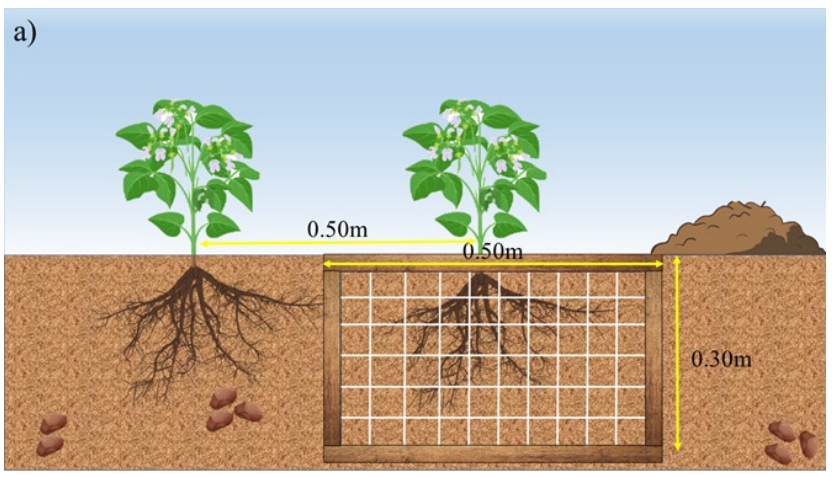

b)

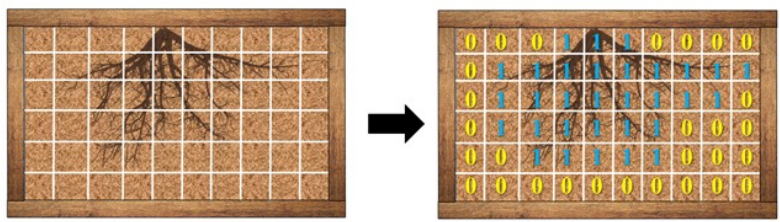

$\%$ roots $=\left(\sum(1) / 60\right) * 100$

Figure 1. a) Front view of the evaluation scheme of the trait root distribution of common bean in the field, assessed to a maximum depth of $0.30 \mathrm{~m}$, at which the genotypes have maximum root development under the field conditions of southern Brazil. In the illustration, plants within rows were spaced $0.50 \mathrm{~m}$ apart, to allow a separate assessment of each plant. b) After taking a picture of the profile, all 60 grid squares on the photograph were assessed in the laboratory for presence or (1) absence of roots (0). Based on the total number of squares with roots, the root percentage in the total evaluated space was determined (60). 


\section{Statistical analysis}

In incomplete block designs, only a subset of the treatments is applied in each block. As a consequence, the differences of treatments will be confused with block effects. Therefore, the source of variation between treatments must include variances within and between blocks. This fact must also be taken into account by the statistical analysis procedures (Littell et al., 2006). The distribution of the response variable root percentage is known as Poisson distribution and belongs to the exponential family. Considering the block effects as random, a generalized linear mixed model was adopted using the PROC GLIMMIX procedure of the SAS (SAS OnDemand for Academics, student version) expressed by the following matrix equation:

$$
\mathrm{y}=\mathrm{XB}+\mathrm{ZU}+\mathrm{e}(\text { Eq. 1) }
$$

Where:

$\mathrm{y}$ : column matrix ( $\mathrm{n} \times 1$ ) of observations;

$\mathrm{X}$ : incidence matrix of fixed effects, known, with 77 columns (one for the intercept, two for replication effects and 74 for treatment effects);

$B$ : vector of fixed replication and treatment effects;

Z: incidence matrix of random effects, known, with 10 columns (block effects);

$\mathrm{U}$ : vector of random block effects;

e: vector of random errors.

To test the genetic effects of interest (additive, dominant and epistatic), predicted functions have been proposed, also known as inference spaces (McLean et al., 1991), using the command ESTIMATE. These inference spaces were established for specific levels (narrow) of the random effect, due to the need to recover information between blocks. Considering the three types of established backcrosses $\left(\mathrm{L}_{1}, \mathrm{~L}_{2}\right.$ and $\left.\mathrm{L}_{3}\right)$, the test for additive $\mathrm{x}$ additive epistasis was initially computed by the predicted function $\mathrm{L}_{1}+\mathrm{L}_{2}-2 \mathrm{~L}_{3}$, for all evaluated progenies ( 1 degree of freedom). The additive effect corresponded to the linear combination $\mathrm{L}_{1}+\mathrm{L}_{2}+\mathrm{L}_{3}$ in the mean of the progenies (1 degree of freedom), while the dominance effects were obtained by the expression $\mathrm{L}_{1 \mathrm{i}}-\mathrm{L}_{2 \mathrm{i}}$ for each $i$-th progeny (24 degrees of freedom). Finally, the effects of additive $\mathrm{x}$ dominant and dominant $\mathrm{x}$ dominant epistasis were estimated simultaneously, by means of an independent scale test $\mathrm{L}_{1 \mathrm{i}}+\mathrm{L}_{2 \mathrm{i}}-2$ $\mathrm{L}_{3 \mathrm{i}}$ for each $i$-th progeny ( 23 degrees of freedom). These functions were calculated by equations proposed by Kearsey and Pooni 1996.

\section{RESULTS}

The possibility of analyzing response variables that do not follow a normal distribution is one of the most relevant advantages of generalized linear mixed models (GLMMs). In this study, the specification of a previously known distribution, based on percentage values (\%) of roots in a given space (grid squares), allowed a considerable reduction of the values of model fit estimates. In particular, the generalized Chi-square value was reduced more than 40 -fold by the specification of the Poisson distribution, compared to the Gaussian distribution (Table 1). In addition, the ratio of the generalized Chi-square value by its degrees of freedom (DF) also decreased, although the value of this 
ratio still indicates some dispersion (Chi-square/DF $>1$ ), for being a measure of the residual variability in the marginal distribution of the data.

Table 1. Analysis of variance for fixed effects and variance components for the random effect for the trait root distribution in common bean and model-fit estimates for Normal and Poisson distributions.

\begin{tabular}{|c|c|c|c|c|}
\hline Source of variation & NDF $^{1}$ & DDF $^{2}$ & F value & $\mathbf{P}>\mathbf{F}$ \\
\hline Replication & 1 & 8 & 0.09 & 0.7683 \\
\hline Treatment & 73 & 202 & 2.75 & 0.0001 \\
\hline Variance component & \multicolumn{2}{|l|}{ Estimate } & \multicolumn{2}{|c|}{ Standard error } \\
\hline Replication (Block) & \multicolumn{2}{|l|}{0.0057} & \multicolumn{2}{|l|}{0.0038} \\
\hline Variable distribution & \multicolumn{2}{|l|}{ Normal } & \multicolumn{2}{|l|}{ Poisson } \\
\hline Generalized Chi-square & \multicolumn{2}{|l|}{37813.46} & \multicolumn{2}{|l|}{869.18} \\
\hline Chi-square /DF & \multicolumn{2}{|l|}{180.06} & \multicolumn{2}{|l|}{4.14} \\
\hline
\end{tabular}

Likewise, the separation between fixed and random effects allowed a combined intra-block analysis with the recovery of information between blocks, which is essential in the analysis of partially balanced incomplete block designs. In these designs, the differences between block totals also provide information about differences between genotypes (Mead, 1997). An adequate specification of the random effect and subsequent combined analysis within and between blocks has a direct influence on the estimated genetic effects and the respective standard errors for each estimate (McLean et al., 1991). In view of this combined analysis, the treatment effect was significant (Table 1). In other words, the genetic variation resulting from the cross between the Mesoamerican genotypes indicates additive and/or non-additive effects that may be of interest for trait root distribution breeding, and consequently, for the selection of superior genetic constitutions.

The significant variation attributable to the fixed treatment factor suggests a complementary analysis to partition the genetic effects of interest. Initially, the genetic values of plants in the population are considered, or simply the variation in genetic values due to additive gene effects (Falconer, 1987). Regardless of this effect, the BLUP value was significant by the $t$ test $(P=0.0001)$, with an estimated standard error of 0.0227 (Table 2). Thus, the genetic constitutions used in the study (BAF50 and IPR Uirapuru) had a mean additive effect (i.e., genes that influence the trait root distribution additively) of $42.60 \%$ (original scale). This value does not fully correspond to the genotypic value of the analyzed 75 progenies, indicating that other causes of genetic variation contribute to trait root distribution inheritance.

Table 2. Incomplete partitioning of the treatment effect for the trait root distribution in common bean. Best linear unbiased predictor (BLUP) for functions that correspond to additive and additive $\mathrm{x}$ additive epistasis (aa) genetic effects.

\begin{tabular}{lllllll}
\hline Genetic effect & NDF $^{\mathbf{1}}$ & DDF $^{\mathbf{2}}$ & BLUP & SE $^{\mathbf{3}}$ & $\mathbf{t}_{\text {value }}$ & $\mathbf{P}>|\mathbf{t}|$ \\
\hline Additive & 1 & 202 & 3.7520 & 0.0227 & 164.75 & 0.0001 \\
Epistasis $a a$ & 1 & 202 & 0.1285 & 0.4919 & 0.26 & 0.7941 \\
\hline
\end{tabular}

$\mathrm{NDF}^{1}$ : Numerator degrees of freedom. $\mathrm{DDF}^{2}$ : Denominator degrees of freedom. $\mathrm{SE}^{3}$ : Standard error. 
For the quantitative trait, a considerable range of phenotypic values was expected, independent of genetic variation (Bos and Caligari, 1995). The absence of this wide expression of genetic and non-genetic effects for the trait root distribution is unlikely. If only the environmental effects are taken into consideration, the soil itself and/or cultivation conditions can be barriers to the various morphological and physiological processes in roots. Thus, as more than one locus is considered in trait expression, the genotypic value may contain an additional deviation caused by additive or non-additive interactions (Falconer, 1987). In this case, the interaction between additive loci indicated no significant effect $(\mathrm{P}=0.7941)$ (Table 2). Compared to the additive component, a 29 times lower estimate of the additive $\mathrm{x}$ additive interaction component was calculated (BLUP $=0.1285)$, associated with a standard error of 0.4919 . In this way, the significance of the deviations associated with additive $\mathrm{x}$ additive epistasis could not be proved for the studied trait.

In addition to the additive $\mathrm{x}$ additive component and aside from the additive effect, other components are the genotypic values of plants in a population. One particularly important component is dominance deviation (Figure 2a). Statistically, deviations due to dominance result from interactions between alleles or interactions within a locus (Falconer, 1987). The partitioning of the treatment effect - according to the genetic design - allows the visualization of the deviations for each $\mathrm{F}_{2}$ progeny under study. The BLUP deviations were estimated between -0.43 and 0.38 . However, significant effects of dominance were only observed for $25 \%$ of the considered progenies (5\% probability). These estimates were based on the recovery of between-block information. If this information were disregarded, significant dominance deviation would be concluded, for example for progeny 24 , which would be inconsistent in view of the high standard error associated with its estimate.

Among the progenies with significant dominance deviations, the deviation of three was positive (progenies 1, 8 and 20) and of three negative (progenies 4, 9 and 18) (Figure 2a). This clearly indicates a situation observed in data of segregating populations, in which, depending on the genetic design, the loci have favorable or unfavorable alleles for trait expression. The analyzed deviations, above all, highlight the advantage of observing the results separately for each progeny. In less sophisticated analyses, the effects of the predicted variation in progenies would be canceled out, given the opposite directions indicated by the plants. If analyzed based on the mean values, the effect of this interaction (progeny $\times L_{1}-L_{2}$ ) would be insignificant (data not shown).

Concomitantly, the deviations provided by non-additive epistasis indicated significant effects in $29 \%$ of the progenies (Figure 2b). However, compared to the dominance deviations, the observed effects reduced the percentage variation by $34 \%$. In other words, for the phenotypic value of roots, these components of the genotypic value are less important than that of the dominance component. Part of these effects is possibly caused by $i$ ) the interaction of genes with additive effects with genes with or without a significant dominance and by $i$ ) the interaction between genes with dominance effects. Given the quantitative nature of the trait and the classic biometric model used here, the genes or regions responsible for these effects could obviously not be identified. However, among the progenies with significant effects, three (progenies 1, 4 and 9) had simultaneous deviations from dominance and non-additive epistasis (Figure $2 \mathrm{a}, \mathrm{b}$ ). In addition, the direction of effects for both dominance and non-additive epistasis was the same for progenies 4 and 9, with the only exception of the values, as mentioned above. Thus, for the said progenies, the genes responsible for the trait root distribution have a dominant effect 
and interact with other genes, however, with comparatively lower effects. On the other hand, progenies 10, 12, 14 and 22 had only non-additive interactions (Figure $2 \mathrm{~b}$ ). In this case, the dominance deviations of the latter three progenies was practically zero (Figure 2 a), and in these cases, epistasis $a d$ and $d d$ may be considered as predominant deviation.

a)

Dominance deviations

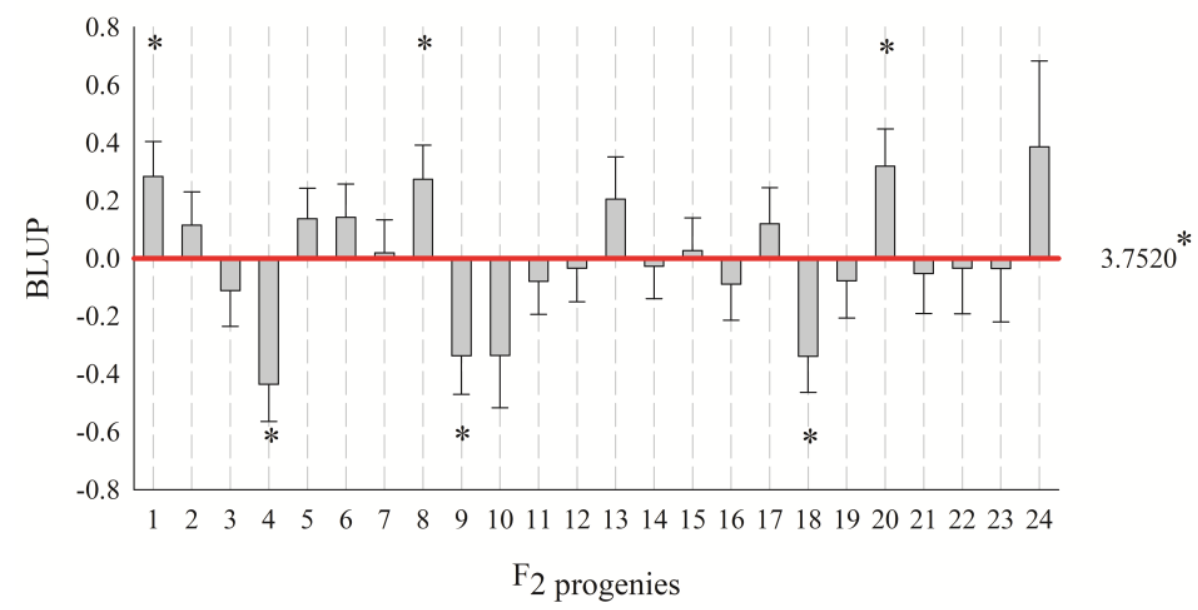

b) Non-additive epistatic deviations $(a d+d d)$

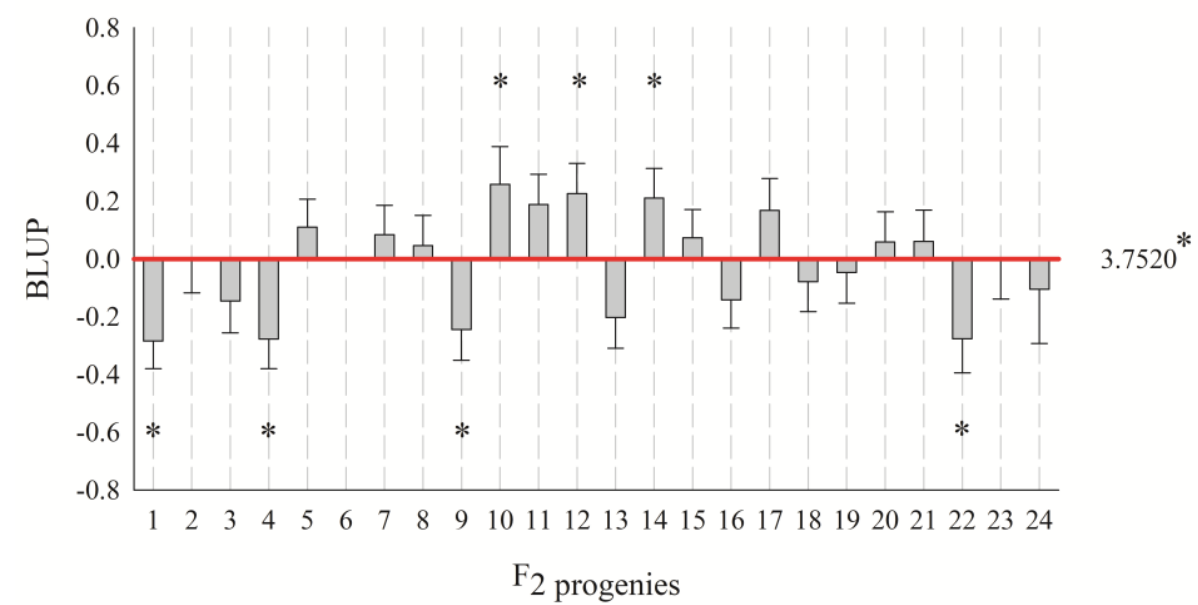

Figure 2. Best linear unbiased predictor (BLUP) for the trait root distribution in common bean. The gray bar (height) represents the value of the genetic component and the black bar the standard error computed by the respective predicted function: a) Dominance deviations calculated for each progeny and b) Non-additive epistatic deviations $(a d+d d)$ calculated for each progeny. The additive genetic value is determined at the point of origin (0.0) for the considered progenies (red line), on the scale of the transformed variable (Poisson distribution). * Deviations significant at $5 \%$ probability by the $t$ test. 
So far, our results reinforce the additive effects on root inheritance in common bean. However, the relationship with shoot traits - mainly grain yield components - may complete the understanding of the evolutionary and breeding processes of each characteristic. The traits number of pods per plant and number of grains per plant were evaluated for these comparisons. Lognormal distribution was considered for both, in which the mean and variance of observations are similar (Steel and Torrie, 1960).

The treatment factor had significant effects on yield components (data not shown). For number of pods per plant, the average additive effect of the progenies was 3.8657, while the additive $\mathrm{x}$ additive interaction effect was insignificant $(\mathrm{P}=0.5684)$ (data not shown). With regard to the non-additive effects, only one dominance deviation (of progeny 10) was significant (Figure 3 a). On the other hand, four significant deviations were found for non-additive epistasis effects (Figure $3 \mathrm{~b}$ ). Compared with the results for the trait root distribution, it was evident that different progenies have dominance and epistasis effects. Therefore, different genes or regions are involved in the expression of root and yield traits of common bean.
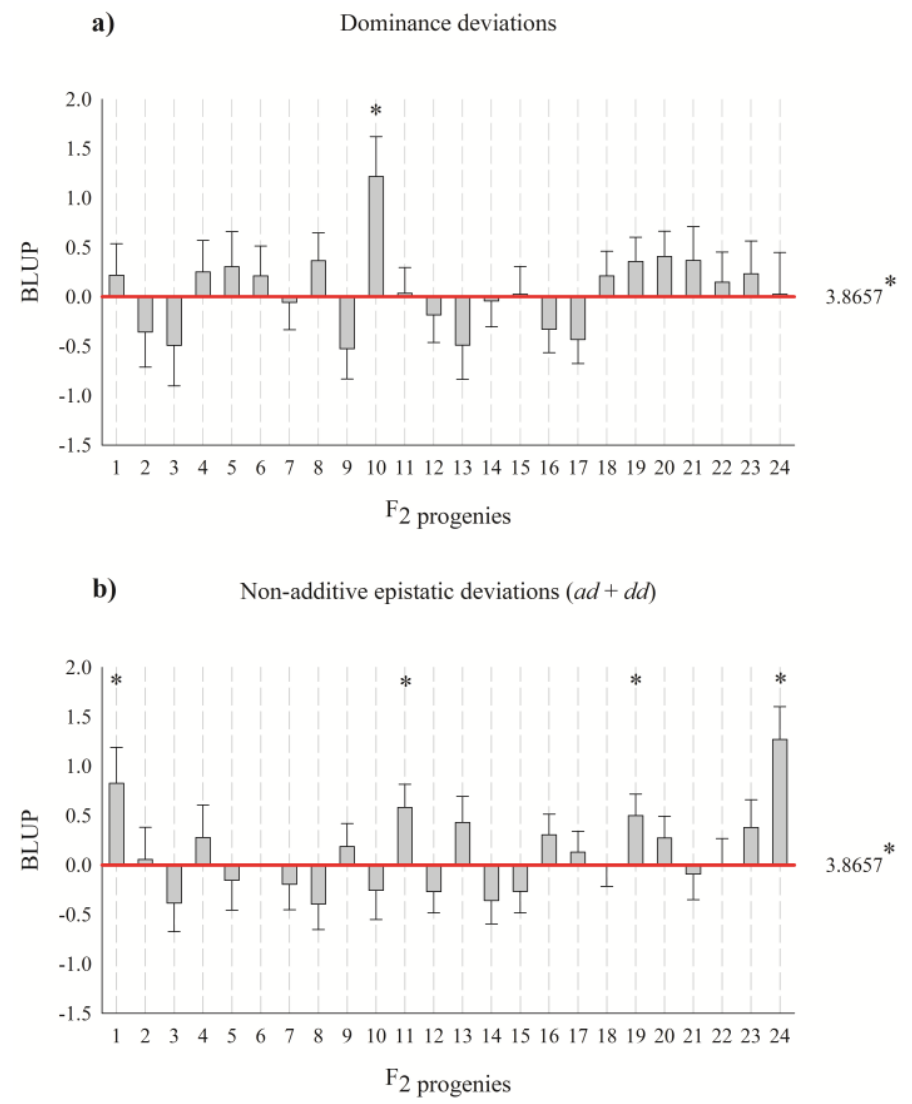

Figure 3. Best linear unbiased predictor (BLUP) for the trait number of pods in common bean. The gray bar (height) represents the value of the genetic component and the black bar the standard error computed by the respective predicted function: a) Dominance deviations calculated for each progeny and b) Non-additive epistatic deviations $(a d+d d)$ calculated for each progeny. At the point of origin (0.0), the additive genetic value is determined for the considered progenies (red line), on the scale of the transformed variable (Lognormal distribution). * Deviations significant at $5 \%$ probability by the $t$ test. 
Similarly, no significant effect for additive $\mathrm{x}$ additive epistasis was detected for the trait number of grains per plant (data not shown). The deviations from dominance and non-additive epistasis however indicated $67 \%$ of association with the deviations found for number of pods per plant (Figures 3 and 4). In other words, the same genetic behavior for both traits was observed in progenies 1, 10, 19 and 24 (Figures 3 and 4). This was to be expected, given the positive correlation between the respective variables (progressive increases in the number of pods progressively increase the number of grains). The comparison between the traits also showed oscillating deviations for the trait root distribution (positive and negative values). For number of pods and number of grains on the other hand, the deviation of all progenies (except progeny 9) was positive. This may indicate that the progenies of the parents used in this study, with significant effects for the shoot trait, have the same favorable alleles.

a)

Dominance deviations

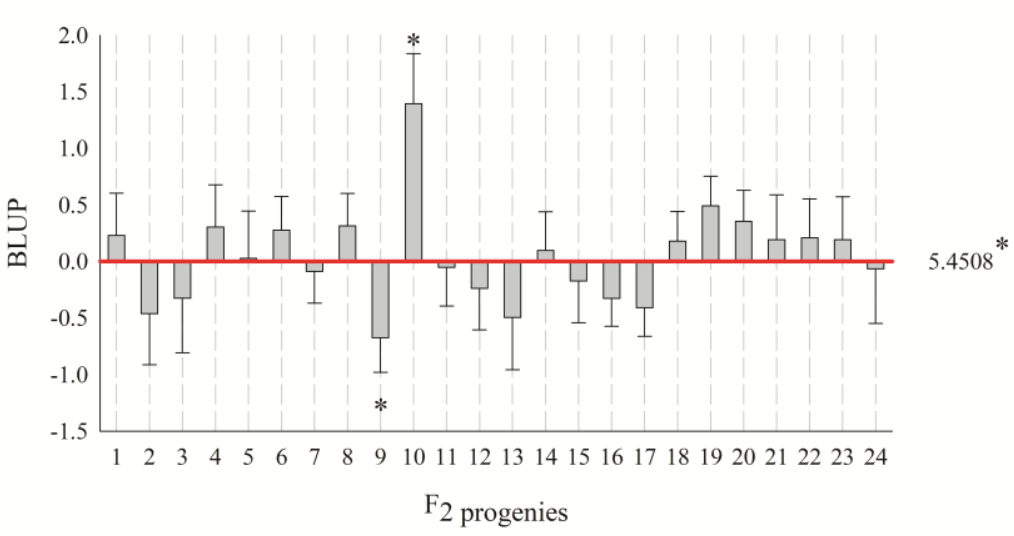

b) Non-additive epistatic deviations $(a d+d d)$

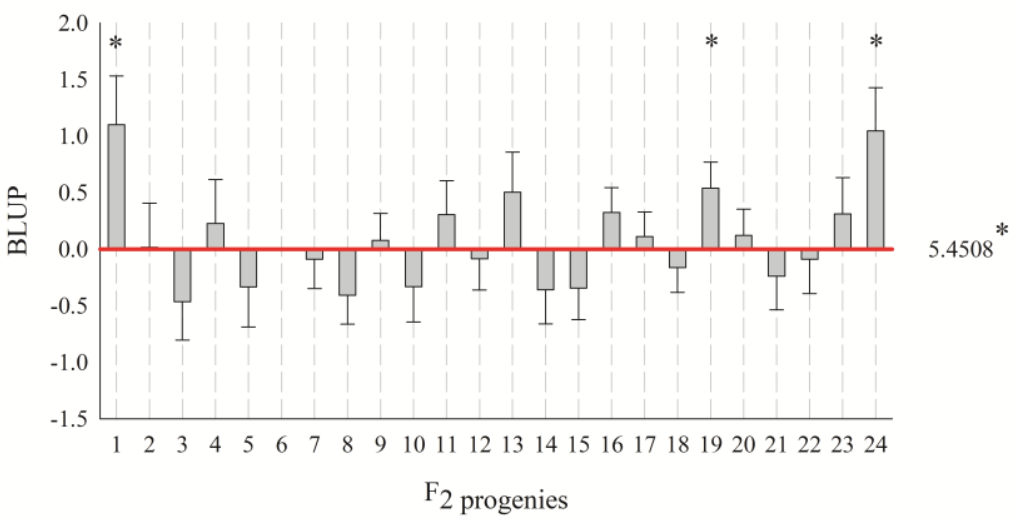

Figure 4. Best linear unbiased predictor (BLUP) for the trait number of grains in common bean. The gray bar (height) represents the value of the genetic component and the black bar the standard error computed by the respective predicted function: a) Dominance deviations calculated for each progeny and b) Non-additive epistatic deviations $(a d+d d)$ calculated for each progeny The additive genetic value is determined at the point of origin (0.0) for the considered progenies (red line), on the scale of the transformed variable (Lognormal distribution). * Deviations significant at $5 \%$ probability by the $t$ test. 


\section{DISCUSSION}

The genetic analysis of the crosses between half-sibs of genotypes of the Mesoamerican gene group indicated that additive inheritance predominates for the traits root, number of pods and number of grains. Therefore, deviations from dominance and from non-additive epistasis represent an insignificant fraction of the genotypic value. In the particular case of root, significant dominance deviation was observed for only $25 \%$ of the progenies and deviations from non-additive interactions (additive $\mathrm{x}$ dominant and dominant $\mathrm{x}$ dominant) for $29 \%$. The deviations observed in the progenies were both positive and negative, contrary to the result for number of pods and number of grains, in which a pattern of positive deviations seems to control the genetic behavior of plants. In addition, dominance and non-additive epistatic deviations indicated an association of $67 \%$ between these traits. Nevertheless, no significant effect of interactions between additive genes could be detected for either trait, although common bean is autogamous.

This study was evaluated under natural cultivation conditions of common bean, according to the technical indications for the crop. However, the rainfall in the evaluated period was excessive $(300-400 \mathrm{~mm}$, total cumulative rainfall during cultivation 545.80 $\mathrm{mm}$ ) as well as poorly distributed. On the other hand, the descriptor "Alumínico" of the local soil can also indicate considerable impairment of the root development. Recent studies have shown effects of aluminum toxicity, causing reductions in numerous trait root distributions of common bean (Ambachew and Blair, 2021). Since the edaphoclimatic conditions of this experiment are common in the main common bean-producing regions, the observed genetic behavior can be reproduced in future trials. However, less water-rich conditions would have allowed a more refined analysis of the genetic components.

Even under the aforementioned conditions, a design that caused a reduction in heterogeneity within blocks was used (Cochran and Cox, 1992). The reason was that the evaluation of 75 treatments under field conditions with replications - in a so-called classic design - would result in a violation of important assumptions of analysis of variance. Owing to computational advances and specific statistical packages, the analysis of factorial experiments in incomplete block designs or the said analysis with fractional replications has become easily accessible, both for research and basic teaching of statistics and experimentation (Mead, 1990).

In addition to the experimental robustness, the genetic design of the chosen method was designed to detect epistasis in quantitative traits. The main utility of the Triple Test Cross is to investigate the genetic architecture of the traits of the population, as well as to estimate the types of genetic actions and interactions and their relationship with selection (Kearsey and Jinks, 1968). However, the method includes the establishment of backcrosses a breeder would not routinely produce in a breeding program, and is therefore considered a resource-consuming design (Nduwumuremyi et al., 2013). Nevertheless, for anyone interested in the genetic architecture of a given trait and in estimating the genetic component with maximum precision, TTC is undoubtedly the most powerful design known. Furthermore, the establishment of the progenies required for this genetic model is not easy, in particular for species such as Phaseolus vulgaris L., in which crosses are labor-intensive and the number of descendants per cross is minimal (Moreto et al., 2012). To ensure efficiency of the genetic analyses, studies suggest that 20 to $40 \mathrm{~F}_{2}$ progenies may be required (Kearsey and Pooni, 1996). In this study, plants were derived from the three 
backcrosses (25 $\mathrm{L}_{1}$ progenies, $25 \mathrm{~L}_{2}$ progenies and $24 \mathrm{~L}_{3}$ progenies), thus respecting the proposed ideal range.

Only sparse classical research on the genetic structure of populations based on the trait root distribution can be found in the literature today. For chickpea (Cicer arietinum), a crop of the same botanical family as common bean, a study based on generation means found that the additive and additive $\mathrm{x}$ additive effects play an important role in the genetic control of the root system (Kashiwagi et al., 2008). In common bean, based on the complete diallel cross design, comparisons between the means of the parents and those of the segregating generations supported the assumption of predominant additive inheritance of the trait root distribution (de Melo et al., 2016, 2018). In addition, it has been found that heterosis is not fundamental for root distribution, even when plants of different gene groups of common bean are crossed; the authors suggested that possible epistatic effects influence this trait (Grigolo et al., 2021). Likewise, a study on the inheritance of common bean root distribution reported significant additive $\mathrm{x}$ additive epistatic effects, with consequent implications for plant selection (Araújo et al., 2005). Although these results agree with ours (predominance of the additive effect), no significant effect for additive $\mathrm{x}$ additive epistasis was detected in this study (Table 2).

For yield or shoot traits of several allogamous and autogamous crops, the literature on genetic effects is abundant. For maize hybrids, reports on the relevance of epistatic effects on grain yield are contradictory. On the one hand, significant effects of up to $21 \%$ of the variation between the means of the evaluated generations were reported (Lamkey et al., 1995), while in contrast, another study stated the absence of epistasis for grain yield in elite hybrids (Hinze and Lamkey, 2003). In studies using the same mating scheme and incomplete block design as in this research, significant effects of epistasis (Barona et al., 2009) and epistasis x location interactions on soybean grain yield were detected (Barona et al., 2012).

More specifically in relation to common bean, the partitioning of epistasis indicated only additive $\mathrm{x}$ dominant and dominant $\mathrm{x}$ dominant types as significant for the traits number of pods and number of grains (Moreto et al., 2012), which corroborates the deviations reported in this study (Figures 3 and 4). In another similar study, epistasis effects were insignificant for grain yield of crosses within the gene group, whereas significant effects both between and within the gene group were observed for 100-grain weight (Borel et al., 2016).

The predominance of additivity in the genetic control of agronomically important traits in autogamous crops is widely known. The main cultivated autogamous species are a mixture of pure lines that accumulate genes in homozygous form. Thus, additive variance is the main component of genetic variation, accounting for around 60 to $90 \%$ for most traits (Toledo et al., 2000); the result expected for the root and grain yield components in common bean would not be different. The fact that significant dominance deviation was detected in approximately $25 \%$ of the $\mathrm{F}_{2}$ progenies (Figure 2 a) was related to the contribution of the heterozygous locus to the total phenotype. Probably, in the respective $F_{2}$ progenies with significant effects, most of the dominant heterozygous and homozygous loci contributed equally to the phenotype. A comparison of backcross generations $\left(\mathrm{L}_{1}-\mathrm{L}_{2}\right)$, shows either favorable or unfavorable effects. Since the direction of these deviations is not uniform, they are easily overlooked when many plants are averaged. Presumably, this phenomenon also occurred for deviations caused by non-additive interactions (Figure $2 \mathrm{~b}$ ), 
and may have been even more accentuated by the lower values of these effects than of dominance deviations.

The fact that significant deviations of dominance and non-additive epistasis in root and yield components were identified in different progenies suggested that different genes or regions are involved in the genetic control of these traits. This finding diverges from the suggested relationship for grain weight and early root development in Andean common beans (Singh et al., 2019). According to these authors, a phenomenon known as developmental pleiotropy occurred during domestication of common bean. This hypothesis presumed that selection for higher grain weight had a significant effect on root growth, resulting in wild genotypes within a gene group with smaller, less branched root systems and with fewer and shorter basal roots than domesticated genotypes.

The dynamics of the appearance of epistatic deviations for these traits can explain the effects on selection in two different scenarios for i) root and ii) yield components. In terms of functional epistasis, i.e., with regard to the dependence on the phenotypic effects of gene substitutions (Falconer, 1987; Hansen, 2013), the following was observed: $i$ ) if there are systematic negative epistatic interactions, so that gene substitutions with positive effects tend to diminish the effects of other positive gene substitutions, the additive variance will decrease with a consequent decrease in the response to selection; ii) in the case of effects of systematic positive epistatic interaction between genes, the substitution of genes with positive effects tends to increase the effects of other gene substitutions with positive effects as well. Under these circumstances, additive genetic variance increases and results in an accelerated response to selection. This may explain certain additional difficulties in breeding for roots compared to shoot traits.

The reason why no trait indicated additive $\mathrm{x}$ additive epistasis may be related to factors such as: i) genetic distance and ii) number of crosses. The parents are considered genetically close, i.e., they belong to the same gene pool (Mesoamerican). As the dominance and epistatic deviations are considered non-additive variations, they imply allelic or gene interactions involving alleles or genes with different effects on the phenotype. The higher the number of crosses, the greater the chances of detecting significant epistatic effects. As this component of the genotypic value will always indicate half of the expected value for the additive component - regardless of the type of family involved in the cross - the increase in the number of crosses will increase the chances of visualizing this small fraction.

The practical value of partitioning genetic components lies in the causes of similarity between relatives. This degree of similarity provides a means of estimating the amount of additive variance, which is intrinsically related to the breeding method to be used (Falconer, 1987). Depending on the type of relationship, different degrees of additive and non-additive fractions are expected. For example, the design of crosses used in this study is based on progenies of half-sib backcrosses. In this case, the genetic covariance will be the variance of half the parental genetic values, corresponding to $1 / 4$ of the additive variance plus $1 / 16$ of the additive $\mathrm{x}$ additive variance. As the component of additive $\mathrm{x}$ additive interaction was insignificant in this study, the total additive variance or genetic value includes only the average genetic effects. In the case of breeding programs for root distribution, the number of generations of evaluation of this trait can be reduced (fewer selfing generations). 
Future studies should include more distant (inter-group) crosses to expand the genetic structure of root distribution and grain yield components in common bean. The progenies derived from crosses within the same gene group (for example Mesoamerican) indicate predominantly additive inheritance for the root and yield components. Progenies with transgressive segregation are more easily detected based on yield components than on the trait root distribution, due to the positive influence of genetic deviations of dominance and additive $\mathrm{x}$ dominant and dominant $\mathrm{x}$ dominant epistasis. In root breeding programs that use crosses between Mesoamerican genotypes, only the mean gene effect (additive effect) should be considered, while gene interactions can be neglected.

\section{ACKNOWLEDGMENTS}

The authors are indebted to the State University of Santa Catarina (UDESC, Brazil), the Brazilian Council for Scientific and Technological Development (CNPq), Brazilian Federal Agency for Support and Evaluation of Graduate Education (CAPES) and Foundation for the Support of the Scientific and Technological Research of Santa Catarina (FAPESC), for a scholarship and funding of this research.

\section{CONFLICTS OF INTEREST}

The authors declare no conflict of interest.

\section{REFERENCES}

Ambachew D and Blair MW (2021). Genome Wide Association Mapping of Trait root distributions in the Andean Genepool of Common Bean (Phaseolus vulgaris L.) Grown With and Without Aluminum Toxicity. Front. Plant Sci. 12: 628687.

Araújo AP, Antunes IF and Teixeira MG (2005). Inheritance of trait root distributions and phosphorus uptake in common bean (Phaseolus vulgaris L.) under limited soil phosphorus supply. Euphytica. 145(1-2): 33-40.

Barona MAA, Filho JMC and Geraldi IO (2009). Epistasia para a produção de grãos em soja. Bragantia. 68(2): 313-318.

Barona MAA, Filho JMC, Santos VS and Geraldi IO (2012). Epistatic effects on grain yield of soybean [Glycine max (L.) Merrill]. Crop Breed. Appl. Biotechnol. 12: 231-236.

Bárzana G and Carvajal M (2020). Genetic regulation of water and nutrient transport in water stress tolerance in roots. $J$. Biotechnol. 324: 134-142.

Bishopp A and Lynch JP (2015). The hidden half of crop yields. Nat. Plants. 1: 15117.

Böhm W (1979). Methods of studying root systems. Berlin: Springer-Verlag.

Borel JC, Ramalho MAP and Abreu AFB (2016). Epistasis in intra- and inter-gene pool crosses of the common bean Genet. Mol. Res. 15(1): 15017573.

Bos IB and Caligari P (1995). Selection methods in plant breeding. London: Chapman \& Hall.

Burridge JD, Findeis JL, Jochua CN, Miguel MA, et al. (2019). A case study on the efficacy of root phenotypic selection for edaphic stress tolerance in low-input agriculture: Common bean breeding in Mozambique. Field Crops Res. 244: 107612

Burridge J, Jochua CN, Bucksch A and Lynch JP (2016). Legume shovelomics: High-Throughput phenotyping of common bean (Phaseolus vulgaris L.) and cowpea (Vigna unguiculata subsp, unguiculata) root architecture in the field. Field Crops Res. 192: 21-32.

Cochran WG and Cox GM (1992). Experimental Designs. 2. ed. Wiley Classics Library.

Falconer DS (1987). Introdução à genética quantitativa. Viçosa: UFV.

Grigolo S, Melo RC, Fioreze ACCL, Guidolin AF, et al. (2021). Heterosis for the root distribution trait in common bean. Acta Sci. - Agron. 43(1): e46712.

Hansen TF (2013). Why epistasis is important for selection and adaptation. Evolution (N. Y). 67(12): 3501-3511.

Heinemann AB, Ramirez-Villegas J, Stone LF and Didonet AD (2017). Climate change determined drought stress profiles in rainfed common bean production systems in Brazil. Agric. For. Meteorol. 246: 64-77.

Hinze LL and Lamkey KR (2003). Absence of Epistasis for Grain Yield in Elite Maize Hybrids. Crop Sci. 43: 46-56. 
Kashiwagi J, Krishnamurthy L, Gaur PM, Chandra S, et al. (2008). Estimation of gene effects of the drought avoidance root characteristics in chickpea (C. arietinum L.). Field Crops Res. 105(1-2): 64-69.

Kearsey MJ and Jinks JL (1968). A general method of detecting additive, dominance and epistatic variation for metrical traits. Heredity. 23(1): 403-409.

Kearsey MJ and Pooni HS (1996). The genetical analysis of quantitative traits. Chapman \& Hall.

Kusterer B, Muminovic J, Utz HF, Piepho HP, et al. (2007). Analysis of a triple testcross design with recombinant inbred lines reveals a significant role of epistasis in heterosis for biomass-related traits in arabidopsis. Genetics. 175(4): 2009-2017.

Lamkey KR, Schnicker BJ and Melchinger AE (1995). Epistasis in a elite maize hybrid and choice of generation for inbred line development. Crop Sci. 35: 1272-1281.

Lanna AC, Mitsuzono ST, Gledson T, Terra R, et al. (2016). Physiological characterization of common bean (Phaseolus vulgaris L.) genotypes, water-stress induced with contrasting response towards drought. AJCS. 10(1): 1-6.

Littell RC, Milliken GA, Stroup WW, Wolfinger RD, et al. (2006). SAS for Mixed Models. 2. ed. Cary, North Carolina: SAS Institute Inc.

McLean RA, Sanders WL and Stroup WW (1991). A unified approach to mixed linear models. Am. Stat. 45(1): 54-64.

Mead R (1990). The Non-Orthogonal Design of Experiments. J. R. Stat. Soc. 153(2): 151-201.

Mead R (1997). Design of plant breeding trials. Statistical Methods for Plant Variety Evaluation. Chapman \& Hall.

Melchinger AE, Utz HF, Piepho HP, Zeng ZB, et al. (2007). The role of epistasis in the manifestation of heterosis: A systems-oriented approach. Genetics. 177(3): 1815-1825.

de Melo RC, Schmit R, Cerutti PH, Guidolin AF, et al. (2016). Genetic variation in the trait root distribution over segregating generations of common bean. Euphytica. 207(3): 665-674.

de Melo RC, Trevisani N, Corrêa SC, Guidolin AF, et al. (2018). Inheritance of root distribution in common bean and selection strategy. Crop Breed. Appl. Biotechnol. 18(4): 373-381.

Moreto AL, Ramalho MAP and Bruzi AT (2012). Epistasis in an Andean $\times$ Mesoamerican cross of common bean. Euphytica. 186(3): 755-760.

Muller B, Guédon Y, Passot S, Lobet G, et al. (2019). Lateral Roots: Random Diversity in Adversity. Trends Plant Sci. 24(9): 810-825.

Nduwumuremyi A, Tongoona P and Habimana S (2013). Mating designs: helpful tool for quantitative plant breeding analysis. J. Plant Breed. Genet. 1(3): 117-129.

Polanía JA, Poschenrieder C, Rao I and Beebe S (2017). Trait root distributions and their potential links to plant ideotypes to improve drought resistance in common bean. Theor. Exp. Plant Physiol. 29(3): 143-154.

Polanía JA, Rao IM, Mejía S, Beebe SE, et al. (2012). Características morfo-físiológicas de frijol común (Phaseolus vulgaris L.) relacionadas con la adaptación a sequía. Acta Agron. 61(3): 197-206.

Rosales MA, Ocampo E, Rodríguez-Valentín R, Olvera-Carrillo Y, et al. (2012). Physiological analysis of common bean (Phaseolus vulgaris L.) cultivars uncovers characteristics related to terminal drought resistance. Plant Physiol. Biochem. 56: 24-34.

Shang L, Liang Q, Wang Y, Zhao Y, et al. (2016). Epistasis together with partial dominance, over-dominance and QTL by environment interactions contribute to yield heterosis in upland cotton. Theor. Appl. Genet. 129(7): 1429-1446.

Shen G, Zhan W, Chen H and Xing Y (2014). Dominance and epistasis are the main contributors to heterosis for plant height in rice. Plant Sci. 215-216: 11-18.

Singh J, Gezan SA and Vallejos CE (2019). Developmental pleiotropy shaped the roots of the domesticated common bean (Phaseolus vulgaris). Plant Physiol. 180(3): 1467-1479.

Steel RGD and Torrie JH (1960). Principles and Procedures of STATISTICS. New York.

Teran JCBMY, Konzen ER, Palkovic A, Tsai SM, et al. (2019). Effect of drought stress on the genetic architecture of photosynthate allocation and remobilization in pods of common bean (Phaseolus vulgaris L.), a key species for food security. BMC Plant Biol. 19(1): 1-15.

Toledo JFF, Arias CAA, De Oliveira MF, Triller C, et al. (2000). Genetical and environmental analyses of yield in six biparental soybean crosses. Pesqui. Agropecu. Bras. 35(9): 1783-1796.

Tracy SR, Nagel KA, Postma JA, Fassbender H, et al. (2020). Crop Improvement from Phenotyping Roots: Highlights Reveal Expanding Opportunities. Trends Plant Sci. 25(1): 105-118. 